\title{
Comparative analysis of the displacement of the soil with different failure modes of excavation
}

\author{
X.W. PENG, D.C. YUAN, M.S.JIANG \\ College of Basic Education, National University of Defense Technology, ChangSha, HuNan, \\ P.R.China,837096576@qq.com
}

Keywords: kick-in; overturn; material point method(MPM); influenced zones; displacement; failure modes.

Abstract:For the pile-wall supporting structure system, the failure modes of the excavation are
different owing to various retaining structures and bracing systems. Thus the displacement of the
soil can be considerably different.By using the material point method, the displacement of the soil
with different failure modes of excavation are analyzed. As a result, the rules of the displacement of
the soil with different failure modes of excavation are proposed.

\section{Introduction}

With the rapid process of urbanization, subway construction scale is expanding in China. During the construction process, subway projects (subway tunnel, foundation pitandconnected aisle) in the high-water-level soft soil area are exposed to high risks. Both in China and abroad,there are plenty of construction accidents ${ }^{[1]}$. Studies abound on the small deformation of the excavation, and the rules of the displacement of the soil are also given ${ }^{[2]}$. As the deformation of the excavation increases, the rules of the displacement of the soil are different. Thus, the displacement of the soil with different failure modes of excavation are analyzed, and the rules of the displacement of the soil are proposed.

Due to the large deformation of soils occurs in the kick-in and overturn of the excavation, if the finite element method was applied to build the model, the mesh distortion would ultimately lead to the termination of the calculation. To overcome this problem, the material point method was employed in an innovative way, for it can avoid mesh distortion problems and suitably analyze large deformation of the metro foundation $\mathrm{pit}^{[3]}$.

\section{Computing model}

For the metro foundation pit is long but narrow, it the can be analyzed by the assumption of plane strain. Considering the symmetry of the model, half the width of foundation pit is suitably to be analyzed .The simplified model of the metro excavation was shown in Fig.1. The diaphragm wall is used in the foundation pit supporting, where the density and thickness of diaphragm are $1600 \mathrm{Kg} / \mathrm{m}^{3}$ and $1 \mathrm{~m}$ respectively. The density and thickness of the lateral bracing are $1600 \mathrm{Kg} / \mathrm{m}^{3}$ and $1 \mathrm{~m}$ respectively.

The horizontal and vertical displacement is constrained at the bottom of the model, and the horizontal displacement is constrained at the two sides. Meanwhile, the soils are simulated based on the Drucker-Prager model, while the diaphragm wall and the lateral bracing are based on the linear elasticity constitutive model ${ }^{[4]}$. According to the related inspection report of the soft soil area, the physical and mechanical indexes of soil are shown in Table 1. 


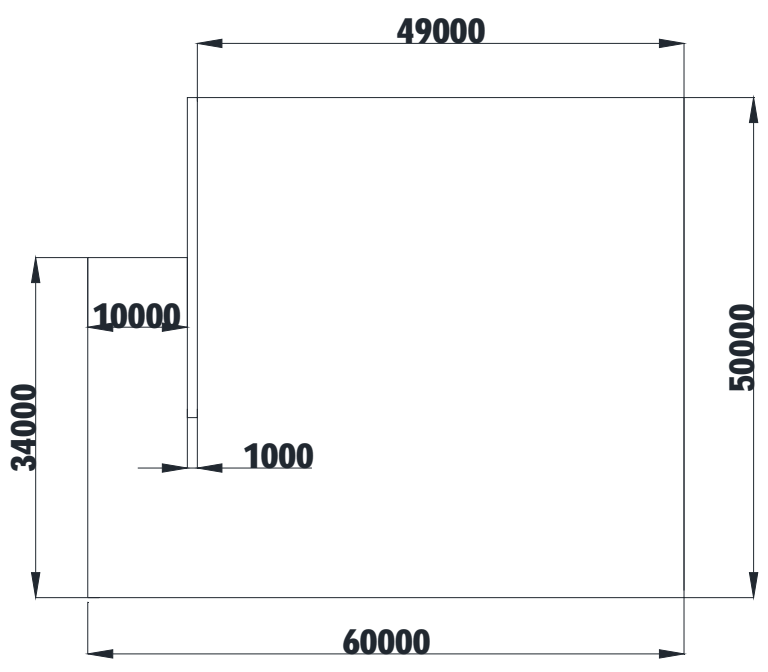

Fig.1The model of the foundation pit (mm)

Table 1. Physical and mechanical parameters of soils ${ }^{[5]}$.

\begin{tabular}{clcccc}
\hline Soils & \multicolumn{1}{c}{$\mathrm{h} / \mathrm{m}$} & $\rho / \mathrm{kg} / \mathrm{m}^{3}$ & $c / \mathrm{kpa}$ & $\Phi /^{\circ}$ & $E / \mathrm{MPa}$ \\
\hline Filling soil & 2 & 1900 & 16.2 & 18.1 & 30 \\
Clayey silt & 5 & 1900 & 10.2 & 31.8 & 30 \\
Silt clay & 12 & 1710 & 15.3 & 13.0 & 10 \\
Mucky silty clay & 16 & 1710 & 13.5 & 13.6 & 15 \\
Silty clay silt & 15 & 1790 & 14.4 & 16.5 & 60 \\
\hline
\end{tabular}

By controlling the excavation depth, parameters of the diaphragm wall and the lateral bracing, the excavations exhibit kick-in and overturn failure modes. The maximum lateral displacement of the diaphragms for kick-in and overturn failure modes are approximately equal to $1.2 \mathrm{~m}$. The parameters of the diaphragm wall and the lateral bracing are shown in Table 2.

Table 2.Parameters of the diaphragm wall and thelateral bracing.

\begin{tabular}{|c|c|c|c|c|c|c|}
\hline \multirow{2}{*}{$\begin{array}{l}\text { Failure } \\
\text { modes }\end{array}$} & \multirow[b]{2}{*}{$(\mathrm{m})$} & \multicolumn{3}{|c|}{ the diaphragm wall } & \multicolumn{2}{|c|}{ thelateral bracing } \\
\hline & & $\begin{array}{c}\mathrm{L} \\
(\mathrm{m})\end{array}$ & $\begin{array}{l}\text { Penetration } \\
\text { depth }(\mathrm{m})\end{array}$ & $\begin{array}{c}E \\
\left(N / m^{2}\right)\end{array}$ & Levels & $\begin{array}{c}E \\
\left(N / m^{2}\right)\end{array}$ \\
\hline Kick-in & -1.23 & 25 & 5 & $3 \mathrm{e} 8$ & $-1 m,-5 m,-9 m$ & $3 \mathrm{e} 7$ \\
\hline overturn & -1.24 & 32 & 16 & $3 \mathrm{e} 9$ & $-9 m,-13 m$ & $3 \mathrm{e} 7$ \\
\hline
\end{tabular}

\section{Analysis of the displacement of soil}

\section{Settlement of soil}

\section{Ground surface settlement}

As shown in Fig.2 and Table 3, the ground surface settlement is arranged in groove shape both in the kick-in and overturn modes, while the curve bending amplitude of the kick-in is bigger than the overturn $^{[6]}$. And the location of the maximumground surface settlement of the overturn is closer to the excavation than the kick-in. For the relative slip between the diaphragm wall and the soil with the overturn, there is great ground surface settlement around the excavation. And the influenced 
zones of the ground surface settlement for the kick-in is larger than the overturn.

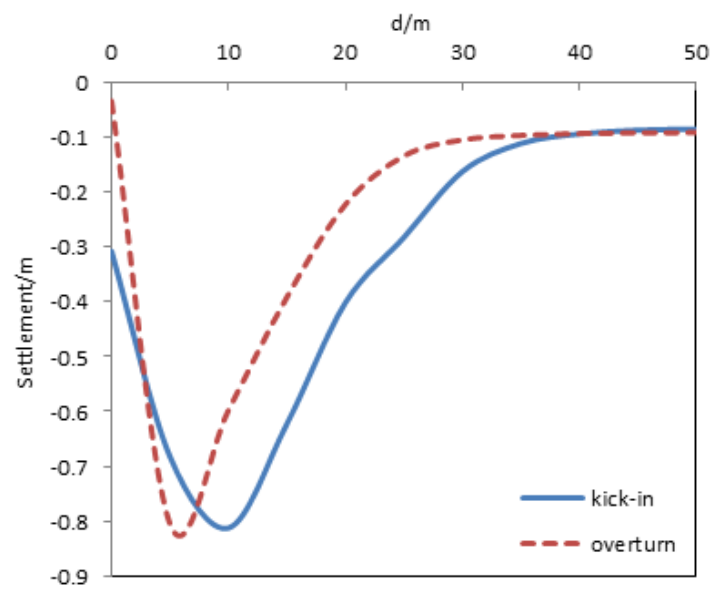

Fig.2 The ground surface settlement with different failure modes of the excavation

Table 3.The maximumground surface settlement and its location.

\begin{tabular}{cccc}
\hline Failure modes & $\begin{array}{c}\text { The maximum lateral } \\
\text { displacement of the } \\
\text { diaphragm }\end{array}$ & $\begin{array}{c}\text { The maximum ground } \\
\text { surface settlement }\end{array}$ & Location \\
\hline Kick-in & $1.23 \mathrm{~m}$ & $0.81 \mathrm{~m}$ & $10 \mathrm{~m}$ \\
\hline overturn & $1.24 \mathrm{~m}$ & $0.83 \mathrm{~m}$ & $6 \mathrm{~m}$ \\
\hline
\end{tabular}

\section{Deep ground settlement}
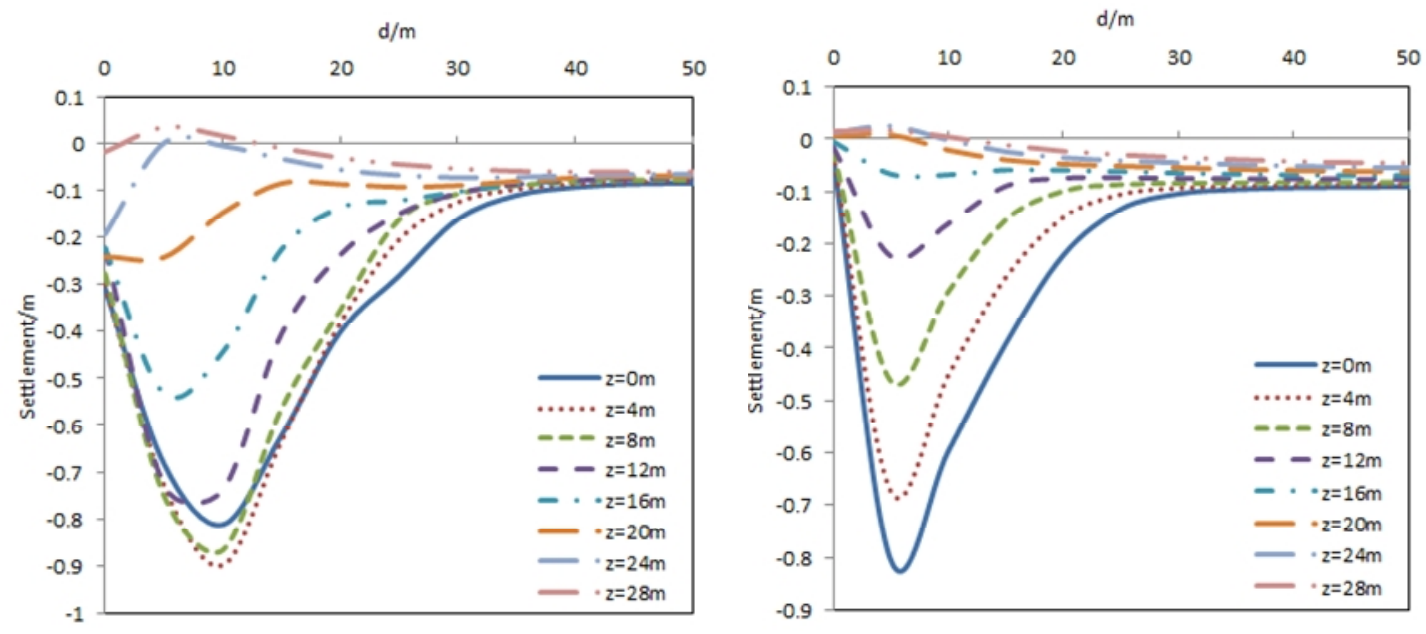

Fig.3 The deep ground settlement (the left is for kick-in, the right is for overturn)

As shown in Fig.3, when the $\mathrm{z} \leq 1 \mathrm{He}$, the settlement curves are similar to the ground surface settlement curve. For the kick-in of the excavation, ground settlement firstly increases and then decreases with the $\mathrm{z}$ increasing. For the overturn of the excavation, ground settlement decreases with the $\mathrm{z}$ increasing. The scope of the the influenced zones decreases with the $\mathrm{z}$ increasing for both the two failure modes.

When the $\mathrm{z}>1 \mathrm{He}$, the deep ground exhibits some degree of rebound deformation, which may be ascribed to soil unloading induced by the excavation. And the rebound deformation of the kick-in is bigger than the overturn, for the kick-in complied with the rebound deformation of the excavation, 
while the diaphragm providing function of blocking rebound deformation for the overturn.

\section{Lateral displacement of soil}

\section{Ground surface lateral displacement}

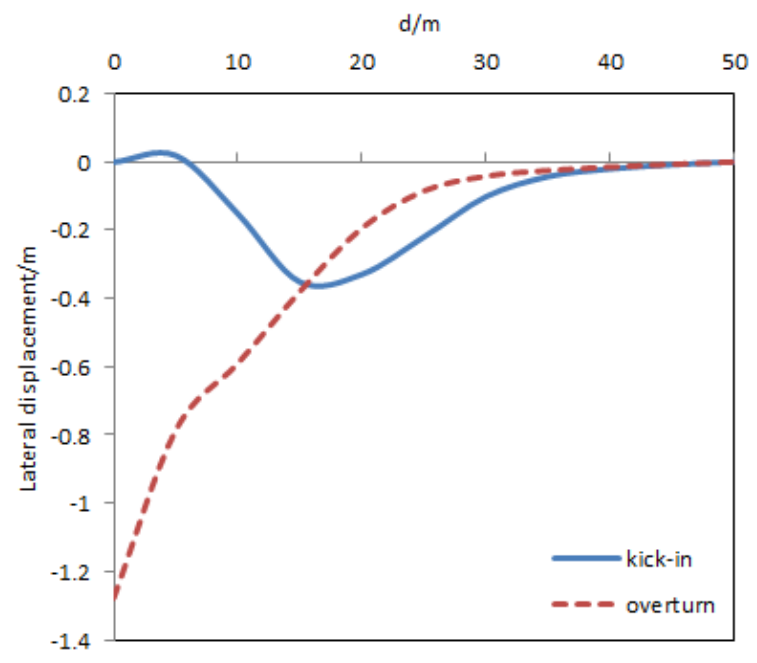

Fig.4 The ground surface lateral displacement with different failure modes of the excavation

Table 4.The maximum ground surface lateral displacementand its location.

\begin{tabular}{cccc}
\hline Failure modes & $\begin{array}{c}\text { The maximum lateral } \\
\text { displacement of the } \\
\text { diaphragm }\end{array}$ & $\begin{array}{c}\text { The maximum ground } \\
\text { surface lateral } \\
\text { displacement }\end{array}$ & Location \\
\hline Kick-in & $1.23 \mathrm{~m}$ & $0.35 \mathrm{~m}$ & $15 \mathrm{~m}$ \\
\hline overturn & $1.24 \mathrm{~m}$ & $1.24 \mathrm{~m}$ & $0 \mathrm{~m}$ \\
\hline
\end{tabular}

As shown in Fig.4 and Table 4, the ground surface lateral displacement is arranged in groove shape for the kick-in, while triangular distribution for the overturn. For the kick-in, the location of the maximum lateral displacement of the diaphragm is $0.75 \mathrm{He}$ away from the excavation, and the lateral displacement of the top of the diaphragm is close to 0 , which may be ascribed to no relative slip between the diaphragm wall and the soil. For the overturn, the location of the maximum lateral displacement of the diaphragm is at the top of the diaphragm, and the influenced degree of the ground surface lateral displacement is larger than that of the kick-in near the excavation. When the $\mathrm{d}<1 \mathrm{He}$, the ground surface lateral displacement for the overturn is bigger than the kick-in.When the $\mathrm{d} \geq 1 \mathrm{He}$, the ground surface lateral displacement for the kick-in is bigger than the overturn. As a result, the influenced zones of the ground surface lateral displacement for the kick-in is larger than the overturn. 


\section{Deep ground lateral displacement}
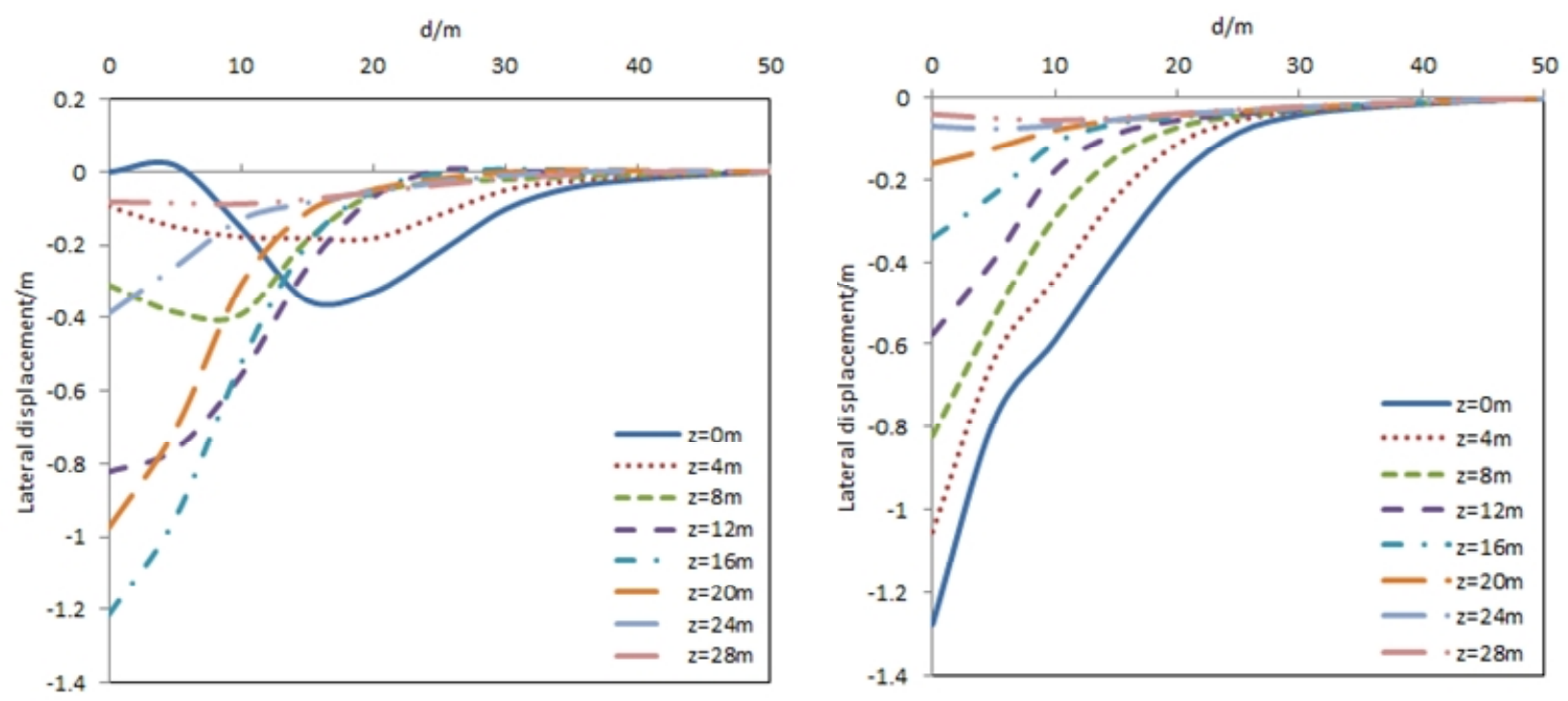

Fig.5 The deep ground lateral displacement (the left is for kick-in, the right is for overturn) As shown in Fig.5, for the kick-in, the curve of the ground lateral displacement changes from the groove shape to the triangular, and the scope of the the influenced zones decreases as the $\mathrm{z}$ increases. When the $\mathrm{z}<0.6 \mathrm{He}$, the ground lateral displacement is arranged in groove shape, and the maximum ground lateral displacement firstly decreases and then increases with the $\mathrm{z}$ increasing. When the $\mathrm{z} \geq 0.6 \mathrm{He}$, the ground lateral displacement is arranged in triangular shape, and the maximum ground lateral displacement firstly increases and then decreases with the $\mathrm{z}$ increasing. For the overturn, the ground lateral displacement is arranged in triangular shape. The ground lateral displacement and the scope of the influences zones decrease with the $\mathrm{z}$ increasing.

\section{Soil displacement field}
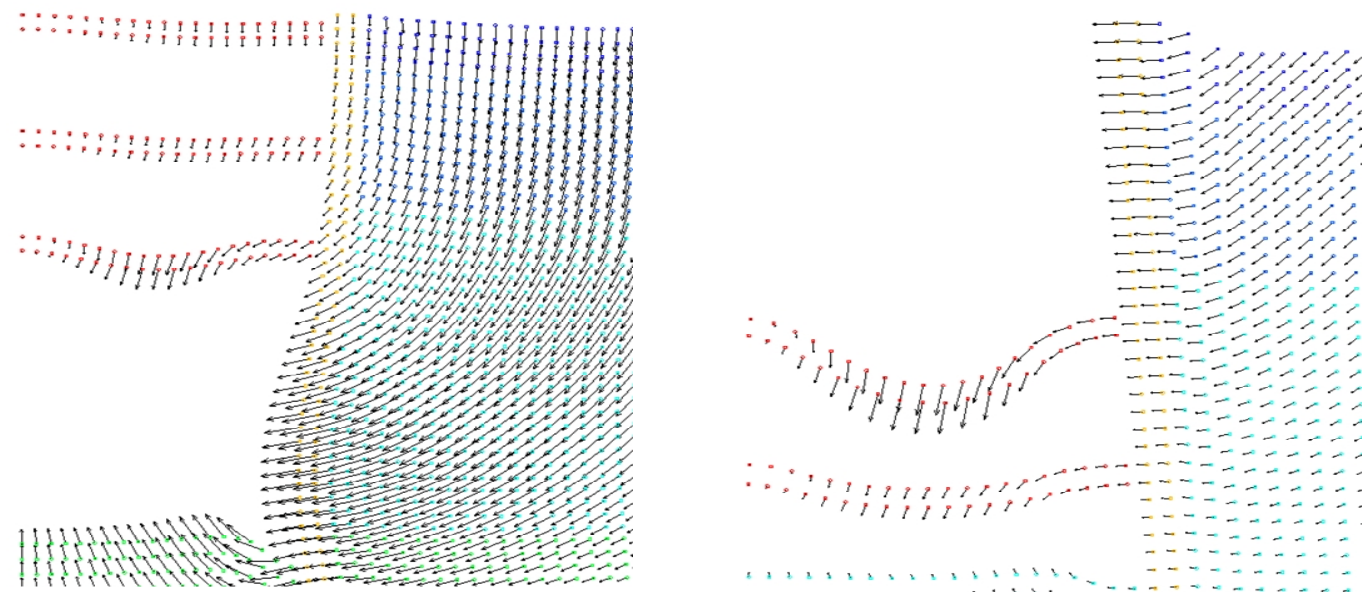

Fig.6 Soil displacement field (the left is for kick-in, the right is for overturn)

As shown in Fig.6, for the kick-in, when the $\mathrm{d} \leq 0.6 \mathrm{He}$, the shallow soil layer mainly shows the settlement. And it changes to lateral displacement with the $\mathrm{z}$ increasing. When the $\mathrm{d}>0.6 \mathrm{He}$, the soil mainly shows the lateral displacement. For the overturn, the ground displacement decreases with the $\mathrm{z}$ and $\mathrm{d}$ increasing, and the soil mainly shows the lateral displacement. Thus, the main influenced zones of the kick-in are the soil around the bottom of the wall, while the main influenced zones of the overturn are the shallow soil close to the excavation. 


\section{Conclusions}

In conclusion, the influenced zones of the ground surface displacement for kick-in of the excavation is larger than overturn of the excavation. And the scope of the influenced zones decreases as the depth increases for kick-in and overturn of the excavation. The main influenced zones of the kick-in are the soil around the bottom of the wall, while the main influenced zones of the overturn are the shallow soil close to the excavation.

\section{References}

[1]Peng,X.W., Yuan,D.C, 2016, "The effect analysis of subway tunnel construction accidents on adjacent buildings."Progress in Civil, Architectural and Hydraulic Engineering, 397-402.

[2]Zheng,Y.R., Qiu,C.Y., 2008, "The exploration of soil tunnel surrounding rock stability analysis method." Chinese Journal of Rock Mechanics and Engineering:27(10).

[3]Lian,Y.P., Zhang,F., liu,Y., 2013, "Theory and application of the material point method."Advances in Mechanics,02:237-264.

[4]Deng,F.H., 2009, "The shield tunnel segment displacement response analysis in the subway operation period." ScienceTechnology and Engineering, 07:3684-3688.

[5]Zheng,G., Li,Z.W., 2012, " Comparison analysis of the effects of foundation pit excavation on adjacent buildings."Chinese Journal of Geotechnical Engineering, 969-977.

[6]Peck,R. B.(1969). Deep excavations and tunneling in soft ground[C]. Proc.7th Int. Conf. SoilMechanical and Foundation Engineering. Mexico City. State of the Art. Vol. pp. 225-290. 